\title{
Association Between Social Capital and Obesity Among Older Adults in China: A Cross-sectional Analysis
}

\section{Le Yang}

Shanxi Medical University https://orcid.org/0000-0003-3466-1854

Jingmin Cheng ( $\square$ chengjingmin@163.com )

Shanxi Medical University

\section{Research article}

Keywords: China, obesity, social capital, the elderly

Posted Date: December 2nd, 2020

DOl: https://doi.org/10.21203/rs.3.rs-117810/v1

License: (c) (1) This work is licensed under a Creative Commons Attribution 4.0 International License.

Read Full License 


\section{Abstract}

Background: Under the global aging trend, health issues of the elderly have received more and more attention. Among them, older adults' obesity is one of the common health problems of the elderly. There are few studies on the association between social capital and obesity in the elderly. We examined whether social capital was associated with obesity in the elderly.

Methods: The data from the Chinese Longitudinal Healthy Longevity Survey (CLHLS) -wave 8 (20172018) was used in this study. Totally, 9551 respondents were included in the final analysis. Generalized trust, informal social interaction and participation of organized social activities were used as measures of social capital. Body mass index (BMI) were used as outcomes. Logistic regression analyses were used to assess associations between the social capital and health outcomes, adjusting for confounders.

Results: We found that the elderly who did not trust people around them had greater odds of being obese compared to those who trust people around them [Adjusted Odds Ratio (AOR) 1.117, 95\% Cl 1.006 to 1.229]. The elderly interacting with friends ( $A O R 1.240,95 \% \mathrm{Cl} 1.006$ to 1.229 ) and participating in organized social activities (AOR 1.182, 95\% $\mathrm{Cl} 1.062$ to 1.301) registered considerably higher BMI.

Conclusions: These results confirm the importance of social capital in older adults' obesity prevention in China, all dimensions of social capital are associated with obesity in the elderly. Furthermore, the positive and negative effects of social capital on obesity in the elderly should be more considered and examined.

\section{Background}

The increase in the elderly population is a worldwide trend. At the end of 2019, the population of China aged 60 and above reached 253.88 million, accounting for $18.1 \%$ of the total population ${ }^{1}$. Due to physical and psychological vulnerability and increased risk of disease, the elderly has more complex health conditions and is currently the focus of health-related research. Among the common diseases in the elderly, obesity is particularly a common health problem ${ }^{2}$. Obesity is a leading metabolic risk factors contribute to increasing the risk of Noncommunicable diseases (NCDs) including cardiovascular diseases such as heart disease and stroke ${ }^{3,4}$, and has always been an important public health issue of concern to countries all over the world. The Report on Nutrition and Chronic Diseases of Chinese Residents (2015) shows the national overweight rate of adults aged 18 and over was $30.1 \%$, and the obesity rate was $11.9 \%$ in 2012 , with an increase of $7.3 \%$ and $4.8 \%$ over 2002 , respectively ${ }^{5}$.

Social capital has gradually appeared in public health research as an important determinant of health. The current approaches in social capital are mainly divided into two dimensions, social cohesion and social network. Social cohesion places more emphasis on social capital at the macro-level, such as social trust, reciprocity and norms, while the social network is mainly concerned with micro-level social capital, such as the density and scope of an individual's social network ${ }^{6,7}$. There are many different perspectives in social capital measures, including cognitive (individuals' perceptions, values, beliefs, and attitudes) 
and structural (externally observable social interactions), bonding (relations between people of groups of similar social identity), bridging (relations between people of groups of different social identity) and linking (formal relations to people of power and authority) ${ }^{8-11}$.

The association between social capital and health has always been the subject of debate and research among scholars. Due to the different measurement dimensions of social capital and the heterogeneity of research groups, there has no unified model and consensus on the measurement and research of social capital. Some studies have found that social capital has a significant positive impact on health, while other studies have found that social capital also has a negative impact on health that cannot be ignored. In general, there are relatively few studies on social capital and obesity, especially obesity in the elderly. Justin et al. (2019) ${ }^{12}$ found that few studies proved the significant association between social capital and obesity after reviewing the literature for the period 2007-2018. While Xin and Ren $(2020)^{2}$ found older adults with higher social capital had had a lower risk of depression but a higher risk of obesity in China using the China Family Panel Studies (CFPS) data.

The purpose of this study is to explore the association between different dimensions of social capital and obesity in the elderly of China, which is vital to provide guidance to health promotion program planners and public health decision makers in obesity and chronic disease prevention in China.

\section{Methods}

\section{Study design}

The present study was a cross-sectional study aimed at identifying the relationships between social capital and obesity of the elderly in China.

\section{Study population}

The cross-sectional data used in this paper is from publicly available source, i.e. from the Chinese Longitudinal Healthy Longevity Survey (CLHLS) -wave 8 (2017-2018). The project covers 23 provinces and is the largest set of survey data of the elderly population in China ${ }^{13}$. CLHLS conducted population surveys with 15,874 individuals in 2017-2018, including rural and urban areas, using a domiciliary faceto-face questionnaire, in the countries' native language. Although the primary target population for the survey was persons aged 65 years and above, the survey included a relatively small sample of respondents aged below 65 years for a comparative purpose. For the purpose of our study, respondents who were under 60 years old from the sample were excluded from our analysis. Although the survey has 15,874 samples in 23 provinces, our analyses in this paper are based on 9551 cases because of incomplete responses.

Of the 9551 cases, body mass index (BMI) was then calculated from the collected data (Table 1). BMI category was calculated using the standard weight status categories from WHO reference ${ }^{14}$. The average 
BMI was $22.57 \mathrm{~kg} / \mathrm{m}^{2}, 1467$ of the elderly $(15.4 \%)$ were underweight, $5765(60.4 \%)$ had an average weight, 1964 (20.6\%) were overweight, and 355 (3.7\%) were obese.

Table 1

Frequency Distribution of BMI of Participants

\begin{tabular}{|llll|}
\hline Variable & $\%$ & $\mathbf{n}$ & Mean (SD) \\
\hline BMI & 100 & 9551 & $22.57(4.41)$ \\
\hline Underweight & 15.4 & 1467 & $16.86(1.37)$ \\
\hline Normal weight & 60.4 & 5765 & $21.78(1.82)$ \\
\hline Overweight & 20.6 & 1964 & $26.92(1.31)$ \\
\hline Obesity & 3.7 & 355 & $34.93(7.12)$ \\
\hline
\end{tabular}

Social capital: In public health researches on social capital and health outcomes, due to the different choices of social capital measures, the research results are also different. The results of research reports focusing on the relationship between collective social capital and health are not that clear, while social capital measures in individual-level is mostly found to be closely related to positive health outcomes ${ }^{15}$. The research is mainly concerned with the impact of individual-level social capital on obesity of the elderly. in this study, we combined elements of different approaches to capture individual-level social capital, such as generalized trust, social network, and social participation, which were shown as important social capital measures associated with health changes and healthcare utilization ${ }^{16-18}$. Social capital was captured using four variables measured: generalized trust (representing cognitive social capital); informal social participation and formal social participation (representing structural social capital).

1 Question about generalized trust: Do you feel that people around you are not trustworthy? The variable response is divided it into three categories ( $1=$ 'to very great or great extent', $2=$ 'moderately', $3=$ 'to very small or small extent').

2 Question about informal social participation: Do you visit and interact with friends regularly? The variable response is divided into $1=$ yes, $2=$ no.

3 Question about formal social participation: Do you take part in social activities (organized) regularly? The variable response is divided into $1=$ yes, $2=$ no.

Covariates: We identified potential confounders a priori from existing literature. The potential confounders included gender, age, years of schooling, marital status, region of residence, household annual income, staple food, smoking, alcohol drinking, and physical activity. Age was grouped into three categories: $60-69,70-79, \geq 80$ years. Years of schooling were categorized into the following four groups: $0-5,6-10,11-15,>15$ years. Marital status was classified into married and living with spouse, 
separate, divorced, widowed, and never married. Region of residence was grouped into three categories: city, town and rural area. Household annual income was categorized as follows: low (< 13680 yuan), medium (13681-60000 yuan), high (> 60000 yuan). Staple food was collapsed into five groups: rice, corn (maize), wheat (noodles, bread, etc.), rice and wheat, and other. Smoking, alcohol drinking, and physical activity were dichotomised, such as smoker and non-smoker.

\section{Statistics}

All data were analyzed using the statistical software package IBM SPSS Statistics version 24 (IBM, Armonk, NY, USA). Descriptive statistics are presented as means and standard deviation (SD), or proportions. The dependent variable was set as the status of BMI (underweight, normal weight/overweight/obesity), Chi-square test was conducted to examine the significant variables. ORs and their confidence intervals were calculated for the association between each independent variable (IV) and the dependent variable, logistic regression was performed to assess the impact of these aforementioned variables on the likelihood that the elderly would be categorized as obese. All models were tested for significance of covariates. The level of significance was set at $P<0.05$.

\section{Results}

The characteristics of the study population are presented in Table 2. Approximately $45.7 \%$ of the participants were men and $54.3 \%$ were women. The prevalence of overweight and obesity in men was $21.7 \%$ and $2.9 \%$, respectively, that in women was $19.6 \%$ and $4.4 \%$, respectively. BMI distribution were statistically different between different age groups $(P<0.001)$, people aged 60-69 years showed higher prevalence of overweight and obesity (37.9\%) than other groups. A higher percentage of older population with high household annual income reported overweight or obese $(P<0.001)$. The elderly with $0-5$ years of schooling reported obviously lower percentage of overweight. The divorced showed higher percentage of overweight but none of them were obese, the separated reported higher percentage of obesity (4.6\%). The prevalence of overweight and obesity in the elderly living in city (31.2\%) was much higher than that of those who living in town (22.0\%) and rural areas (21.9\%). People whose staple food was wheat (noodles, bread, etc.) reported higher prevalence of overweight and obesity $(29.4 \%)$ than others, while only $21.0 \%$ of people who ate rice as their staple food reported overweight or obesity. Non-smoker and nondrinker reported higher rates of obesity $(P<0.01)$. Obesity accounted for a higher proportion of people who exercised $(P<0.001)$. 
Table 2

Descriptive statistics of study population

\begin{tabular}{|c|c|c|c|c|c|c|}
\hline Variable & $\mathrm{n}$ & $\begin{array}{l}\text { Underweight } \\
(\%)\end{array}$ & $\begin{array}{l}\text { Normal } \\
(\%)\end{array}$ & $\begin{array}{l}\text { Overweight } \\
(\%)\end{array}$ & $\begin{array}{l}\text { Obesity } \\
(\%)\end{array}$ & $\begin{array}{l}\mathrm{p} \\
\text { value }\end{array}$ \\
\hline \multicolumn{7}{|l|}{ Gender } \\
\hline Male & 4362 & 12.3 & 63.0 & 21.7 & 2.9 & \multirow[t]{2}{*}{$<0.001$} \\
\hline Female & 5189 & 17.9 & 58.1 & 19.6 & 4.4 & \\
\hline \multicolumn{7}{|l|}{ Age } \\
\hline $60-69$ & 1299 & 4.2 & 57.8 & 33.4 & 4.5 & \multirow[t]{3}{*}{$<0.001$} \\
\hline $70-79$ & 2608 & 8.0 & 58.9 & 28.1 & 5.1 & \\
\hline$\geq 80$ & 5644 & 21.3 & 61.6 & 14.1 & 2.9 & \\
\hline \multicolumn{7}{|c|}{ Household annual income (yuan) } \\
\hline$<13680$ & 3184 & 16.4 & 61.5 & 18.4 & 3.7 & \multirow[t]{3}{*}{$<0.001$} \\
\hline $13681-60000$ & 3537 & 16.8 & 60.0 & 19.7 & 3.5 & \\
\hline$>60000$ & 2830 & 12.4 & 59.5 & 24.0 & 4.1 & \\
\hline \multicolumn{7}{|l|}{ Years of schooling } \\
\hline $0-5$ & 6535 & 18.4 & 60.6 & 17.6 & 3.4 & \multirow[t]{4}{*}{$<0.001$} \\
\hline $6-10$ & 2189 & 9.3 & 59.3 & 27.0 & 4.4 & \\
\hline $11-15$ & 656 & 6.9 & 61.1 & 27.4 & 4.6 & \\
\hline$>15$ & 171 & 9.9 & 61.4 & 25.7 & 2.9 & \\
\hline \multicolumn{7}{|l|}{ Marital status } \\
\hline $\begin{array}{l}\text { Married and living with } \\
\text { spouse }\end{array}$ & 4338 & 8.9 & 60.8 & 26.2 & 4.1 & \multirow[t]{5}{*}{$<0.001$} \\
\hline Separated & 174 & 17.2 & 60.3 & 17.8 & 4.6 & \\
\hline Divorced & 28 & 17.9 & 57.1 & 25.0 & 0.0 & \\
\hline Widowed & 4941 & 21.0 & 59.8 & 15.8 & 3.4 & \\
\hline Never married & 70 & 11.4 & 70.0 & 15.7 & 2.9 & \\
\hline \multicolumn{7}{|l|}{ Current residential area } \\
\hline City & 2393 & 10.4 & 58.3 & 26.0 & 5.2 & \multirow[t]{2}{*}{$<0.001$} \\
\hline Town & 3138 & 17.2 & 60.8 & 18.8 & 3.2 & \\
\hline
\end{tabular}




\begin{tabular}{|c|c|c|c|c|c|c|}
\hline Rural area & 4020 & 16.8 & 61.2 & 18.7 & 3.2 & \\
\hline \multicolumn{7}{|l|}{ Staple food } \\
\hline Rice & 5720 & 17.4 & 61.6 & 18.0 & 3.0 & \multirow[t]{5}{*}{$<0.001$} \\
\hline Corn (maize) & 398 & 16.1 & 54.8 & 23.6 & 5.5 & \\
\hline Wheat (noodles, bread, etc.) & 1573 & 9.9 & 60.8 & 24.6 & 4.8 & \\
\hline Rice and wheat & 1791 & 13.1 & 58.0 & 24.3 & 4.6 & \\
\hline Other & 69 & 29.0 & 40.6 & 26.1 & 4.3 & \\
\hline \multicolumn{7}{|l|}{ Smoking } \\
\hline Smoker & 1533 & 15.8 & 64.6 & 17.9 & 1.7 & \multirow[t]{2}{*}{$<0.001$} \\
\hline Non-smoker & 8018 & 15.3 & 59.6 & 21.1 & 4.1 & \\
\hline \multicolumn{7}{|l|}{ Alcohol drinking } \\
\hline Drinker & 1471 & 12.8 & 62.8 & 21.8 & 2.5 & \multirow[t]{2}{*}{$<0.01$} \\
\hline Non-drinker & 8080 & 15.8 & 59.9 & 20.3 & 3.9 & \\
\hline \multicolumn{7}{|l|}{ Physical activity } \\
\hline Yes & 3349 & 10.6 & 59.3 & 25.9 & 4.2 & \multirow[t]{2}{*}{$<0.001$} \\
\hline No & 6202 & 17.9 & 60.9 & 17.7 & 3.5 & \\
\hline \multicolumn{7}{|c|}{ Generalized trust (people around are not trustworthy) } \\
\hline Very great or great extent & 1499 & 15.1 & 57.3 & 22.9 & 4.6 & \multirow[t]{3}{*}{$<0.05$} \\
\hline Medium & 1094 & 14.5 & 62.7 & 19.1 & 3.7 & \\
\hline Very small or small extent & 6958 & 15.5 & 60.6 & 20.3 & 3.5 & \\
\hline \multicolumn{7}{|l|}{ Interaction with friends } \\
\hline Yes & 5833 & 12.2 & 61.2 & 23.0 & 3.7 & \multirow[t]{2}{*}{$<0.001$} \\
\hline No & 3718 & 20.4 & 59.1 & 16.8 & 3.7 & \\
\hline \multicolumn{7}{|c|}{ Participation of organized social activities } \\
\hline Yes & 1510 & 7.7 & 58.5 & 29.4 & 4.3 & \multirow[t]{2}{*}{$<0.001$} \\
\hline No & 8041 & 16.8 & 60.7 & 18.9 & 3.6 & \\
\hline
\end{tabular}

A majority of respondents had some trust in people around them, about $15.7 \%$ of the participants reported people around them were not trustworthy to very great or great extent, more than one-third of the 
elderly had no interaction with friends, and about $84.2 \%$ of the elderly had never participated in organized social activities.

Ordinal logistic regressions on BMI as a dependent variable were carried out (Table 3). Models 1-3 examine the association between each component of social capital and BMI after controlling for sociodemographic, socioeconomic characteristics and some influencing health behaviours by putting each component of social capital into the model one by one: no confounder was controlled in Model 1 , gender, age, years of schooling, marital status, residence area, and household annual income were controlled in Model 2, and Model 3 examines the association between all components of social capital and BMI with adjustment for staple food, smoke, alcohol drink, and physical activity in addition to the confounders in Model 2. 
Table 3

Odds ratios (95\% confidence Intervals) for respondents reporting obesity

Model 1 (Crude OR)

Model $2^{\mathrm{a}}$

Model $3^{b}$

Generalized trust (people around are not trustworthy)

\begin{tabular}{|c|c|c|c|}
\hline Very great or great extent & $1.137 *(1.027-1.246)$ & $\begin{array}{l}1.111(0.995- \\
1.226)\end{array}$ & $\begin{array}{l}1.117 *(1.006- \\
1.229)\end{array}$ \\
\hline Moderately & $0.993(0.868-1.118)$ & $\begin{array}{l}0.960(0.832- \\
1.087)\end{array}$ & $\begin{array}{l}0.994(0.867- \\
1.121)\end{array}$ \\
\hline Very small or small extent & 1.00 & 1.00 & \\
\hline \multicolumn{4}{|l|}{ Interaction with friends } \\
\hline Yes & $\begin{array}{l}1.451 * * \star(1.366- \\
1.535)\end{array}$ & $\begin{array}{l}1.232^{\star * *}(1.146- \\
1.319)\end{array}$ & $\begin{array}{l}1.240 * \star *(1.152- \\
1.328)\end{array}$ \\
\hline No & 1.00 & 1.00 & \\
\hline
\end{tabular}

Participation of organized social activities

$\begin{array}{llll}\text { Yes } & 1.670 * * *(1.561- & 1.196 * *(1.078- & 1.182 * *(1.062- \\ 1.780) & 1.314) & 1.301) \\ \text { No } & 1.00 & & 1.00\end{array}$

${ }^{\star} p<0.05 ; \star \star p<0.01 ; * \star \star p<0.001$; Results are from proportional odds models. Results are displayed as ORs of change in BMI status (contrasting increase vs constant high/low or decrease; or increase or constant high/low vs decrease) per unit increase in the original scale of generalized trust, interaction with friends or in participation of organized social activities. ORs $>1$ indicate a positive change in the outcome as a response to an improvement of exposure.

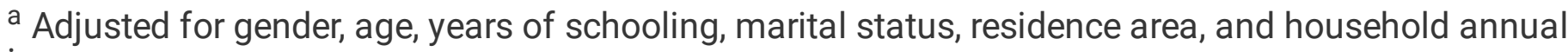
income.

${ }^{\mathrm{b}}$ Adjusted for gender, age, years of schooling, marital status, residence area, household annual income, staple food, smoking, alcohol drinking, and physical activity.

The elderly who did not trust people around them had greater odds of being obese at Model 1 [Odds Ratio (OR) 1.137, $95 \%$ Confidence Interval $(95 \% \mathrm{Cl}) 1.027$ to 1.246]. After adjusting for confounders (gender, age, years of schooling, marital status, residence area, household annual income, staple food, smoking, alcohol drinking, and physical activity), a slightly lower odds were observed in Model 3 [Adjusted Odds Ratio (AOR) 1.117, 95\% Cl 1.006 to 1.229].

Among the interaction with friends categories, the elderly interacting with friends (OR $1.451,95 \% \mathrm{Cl} 1.366$ to 1.535) registered considerably higher BMI compared to those who did not at Model 1, and slightly lower odds were observed in Model 3 (AOR 1.240, 95\% Cl 1.152 to 1.328). 
And significant association between participation of organized social activities and obesity was found, the group who participated organized social activities $67.0 \%$ higher odds of being obese (OR 1.670, $95 \%$ $\mathrm{Cl} 1.561$ to 1.780), and the AOR was decreased slightly after controlling for all potential confounders (AOR $1.182,95 \% \mathrm{Cl} 1.062$ to 1.301 ).

In summary, those with lower generalized trust and social participation showed higher BMI, i.e. obesity when gender, age, years of schooling, marital status, residence area, household annual income, staple food, smoking, alcohol drinking, and physical activity were taken into account.

\section{Discussion}

Our findings suggest that two subdimensions of social capital (i.e., generalized trust, social participation) has a significant relationship with obesity among older adults in China.

Generalized trust: As far as we know, the finding reported in the presence study is the first to investigate associations between generalized trust and the elderly's obesity in China. We find evidence that low level of generalized trust was significantly associated with higher odds of obesity. Due to different measurement indicators, there may be differences in research results. Many studies focus on the correlation between generalized trust and self-rated health (or self-reported health, SRH) or mental health, but this study uses more specific indicators, i.e. BMI. The finding is somewhat consistent with the findings of Wu et al. ${ }^{19}$, in their study, generalized trust was associated with lower risk of obesity. There could be at least two interpretations of the association between generalized trust and the elderly's obesity. First, social capital's buffering of psychological pressure ${ }^{20,21}$. When the generalized trust level of the elderly is low, they are more likely to feel uneasy and lonely, their psychological pressure cannot be effectively buffered by social capital, so there is a relatively high possibility of obesity caused by stressrelated eating ${ }^{22}$. Second, a low level of generalized trust leads to a lower level of safety among residents and poor social control ${ }^{23}$, which will hinder the promotion of healthy behaviors and the dissemination of information.

Social participation: What the research found is the negative effect of social participation (formal and informal) on obesity. The finding indicates that contact with friends and participate in organized social activities increases the likelihood of being obese in the elderly of China. Many studies have confirmed the social contagion of unhealthy behaviors in social interactions ${ }^{24-27}$. From the perspective of social contagion, unhealthy eating behavior, such as unhealthy dietary habits, can be promoted among the elderly through frequent social interaction, especially in the context of Chinese social culture, friends mainly socialize through meals. In addition, frequent social interaction will increase the incidence of obesity-risk behaviors such as occasion drinking ${ }^{28}$ and smoking. It should also be noted that the differences in social capital between different genders under the influence of factors such as traditional social roles and social responsibilities. Women has more close relationship with their family members and friends, while men tend to rely more on social connections through the workplace and participation in 
organizations ${ }^{29}$. Hence, the reasons and mechanism for relationship between social participation and obesity in different genders may be different and needs to be explored in future studies.

\section{Conclusions}

Our research found that different social capital has different relationships with obesity. The associations between different social capital measures and obesity of the elderly need further study. There is no health promotion model uniformly applicable for all the elderly of China. Different elderly groups have their own particularities, so the policy makers should adopt different targeted health promotion strategies. In the process of formulating social capital interventions for obesity in the elderly, more attention needs to be paid to the positive affection of generalized trust and the negative affection of social participation.

\section{List Of Abbreviations}

Chinese Longitudinal Healthy Longevity Survey (CLHLS)

Body mass index (BMI)

Adjusted Odds Ratio (AOR)

Noncommunicable diseases (NCDs)

Standard deviation (SD)

Odds Ratio (OR)

95\% Confidence Interval $(95 \% \mathrm{Cl})$

Self-reported health (SRH)

\section{Declarations}

\section{Ethics approval and consent to participate}

For the data was extracted from the Chinese Longitudinal Healthy Longevity Survey (CLHLS), ethical approval was not required.

\section{Consent for publication}

This paper is our original unpublished work and it has not been submitted to any other journal for reviews. All authors are in agreement with the content and the submission of the manuscript.

\section{Availability of data and material}


PKU Centre for Healthy Ageing and Development. 2020. "Chinese Longitudinal Healthy Longevity Survey (CLHLS).” Peking University Open Research Data. https://doi.org/10.18170/DVN/WBO7LK.

\section{Competing interests}

On behalf of all authors, the corresponding author states that there is no conflict of interest.

\section{Funding}

This study did not receive funding from any source.

\section{Authors' contributions}

Le Yang conceived and designed the study analyzed the data and contributed to original draft; Jingmin Cheng contributed to review and revision of the manuscript. All authors read and approved the final manuscript.

\section{Acknowledgements}

We greatly appreciate the data shared by PKU Centre for Healthy Ageing and Development, and the support and advices from the reviewers and the editors.

\section{References}

1. National Bureau of Statistics of China. Statistical Communiqué of the People's Republic of China on the 2019 National Economic and Social Development [Cited 21 September 2020.] Available from: http://www.stats.gov.cn/english/PressRelease/202002/t20200228_1728917.html.

2. Xin Y, Ren X. Social Capital as a Mediator through the Effect of Education on Depression and Obesity among the Elderly in China. Int J Environ Res Public Health. 2020;17(11): 3977.

3. Obesity. World Health Organization. [Cited 21 September 2020.] Available from: https://www.who.int/health-topics/obesity\#tab=tab_2.

4. Poirier P, Giles TD, Bray GA et al. Obesity and cardiovascular disease: Pathophysiology, evaluation, and effect of weight loss. 2006;113(6): 898-918.

5. National Health Commission of the People's Republic of China. Report on Nutrition and Chronic Diseases of Chinese Residents (2015). (In Chinese). [Cited 21 September 2020.] Available from: http://www.nhc.gov.cn/jkj/s5879/201506/4505528e65f3460fb88685081ff158a2.shtml.

6. Mohammadi MR, Hooshyari Z, Ezanloo B et al. Application of Different Techniques of Factor Analysis to Develop Neighborhood Social Capital Rating Scale. Soc Indic Res. 2020; 150: 375-391.

7. Moore S, Kawachi I. Twenty years of social capital and health research: a glossary. Journal of Epidemiology and Community Health. 2017; 71(5): 513-517.

8. Coleman JS. Social capital in the creation of human capital. Am J Sociol. 1988; 94: 95-120. 
9. Putnam RD. Bowling Alone: the Collapse and Revival of American Community. New York: Simon \& Schuster; 2000.

10. Szreter S, Woolcock M. Health by Association? Social capital, social theory and the political economy of public health. J. Epidemiol. 2004; 33: 650e667.

11. Harpham T, Grant E, Thomas E. Measuring social capital within health surveys: key issues. Health Policy Plan. 2002; 17 (1): 106e111.

12. Rodgers J, Valuev AV, Hswen Y, Subramanian SV. Social capital and physical health: An updated review of the literature for 2007-2018. Soc Sci Med. 2019; 236: 112360.

13. Yang Y, Meng Y. Is China Moving toward Healthy Aging? A Tracking Study Based on 5 Phases of CLHLS Data. J. Environ. Res. Public Health. 2020; 17(12): 4343.

14. World Health Organization. Obesity and overweight [Cited 21 September 2020.] Available from: https://www.who.int/news-room/fact-sheets/detail/obesity-and-overweight.

15. Xue X, Reed WR, Menclova A. Social capital and health: a meta-analysis. Journal of Health Economics. 2020;72: 102317.

16. Giordano GN, Lindstrom M. The impact of changes in different aspects of social capital and material conditions on self-rated health over time: a longitudinal cohort study. Social Science \& Medicine. 2010; 70 (5): 700-710.

17. Moore S, Carpiano MR. Measures of personal social capital over time: A path analysis assessing longitudinal associations among cognitive, structural, and network elements of social capital in women and men separately. Social Science \& Medicine. 2020; 257: 112172.

18. Herberholz C, Phuntsho S. Social capital, outpatient care utilization and choice between different levels of health facilities in rural and urban areas of Bhutan. Social Science \& Medicine. 2018; 211: 102-113.

19. Wu YH, Moore S, Dube L. Social capital and obesity among adults: longitudinal findings from the Montreal neighborhood networks and healthy aging panel. Prev Med. 2018; 111: 366-370.

20. Phongsavan P, Chey T, Bauman A, Brooks R, Silove D. Social capital, social-economic status and psychological distress among Australian adults. Social Science \& Medicine. 2006; 63: 2546-2561.

21. Shiell A, Hawe P, Kavanagh S. Evidence suggests a need to rethink social capital and social capital interventions. Social Science \& Medicine. 2020; 257: 111930.

22. Cotter EW, Kelly NR. Stress-related eating, mindfulness, and obesity. Health Psychol. 2018; 37(6): 516-525.

23. Bamford J, Klabbers G, Curran E, Rosato M, Leavey G. Social Capital and Mental Health Among Black and Minority Ethnic Groups in the UK. J Immigr Minor Health 2020. Doi: https://doi.org/10.1007/s10903-020-01043-0.

24. Kumar PC, McNeely J, Latkin CA. "It's not what you know but who you know": role of social capital in predicting risky injection drug use behavior in a sample of people who inject drugs in Baltimore city. Subst. Use. 2016; 21: 620-626. 
25. Caspi CE, Kawachi I, Subramanian SV, Tucker-Seeley R, Sorensen G. The social environment and walking behavior among low-income housing residents. Social Science \& Medicine. 2013; 80: 76-84.

26. Li S, Delva J. Social capital and smoking among Asian American men: an exploratory study. J. Public Health. 2012; 102 (Suppl. 2): S212-S221.

27. Mellor JM, Freeborn BA. Religious participation and risky health behaviors among adolescents. Health Econ. 2011; 20: 1226-1240.

28. Seid AK, Hesse M, Bloomfield K. 'Make it another for me and my mates': does social capital encourage risky drinking among the Danish general population? Scand. Public Health. 2016; 44: 240-248.

29. Norris P, Inglehart R. Gender and social capital. In: O'Neill, B., Gidengil, E. (Eds.), Gender and Social Capital. New York: Routledge; 2006. 